\title{
Maintenance of Buildings Using BIM Methodology
}

\author{
A.Z. Sampaio* and Diogo Simões
}

\author{
Department of Civil Engineering, IST, ICIST, University of Lisbon, Lisbon, Portugal
}

\begin{abstract}
Building maintenance is the responsibility of its owner which must use, whenever appropriate, a technician to perform the inspection. A good maintenance depends on the analysis of the anomalies detected during the inspection of the site. Building Information Models (BIM) have revealed themselves as a good tool when it comes to supporting maintenance actions, due to their ability to store enough information in one digital model. The aim of the proposed work was to implement the benefits provided by BIM on a software tool used as support to maintenance of buildings. During an inspection activity for maintenance purposes, the implemented application, containing a rigorous database, allows the user to identify each anomaly present in building components, directly onto the BIM model, automatically associating them with probable causes, repair methods and a photograph of the anomaly uploaded at the site. Therefore, gains in productivity and a decrease in the error probability can be achieved. The inspection data is stored in the BIM model, making it suitable for consultation when planning maintenance. Additionally, it was case study the interoperability between BIM modeling and visualizing software, regarding the preservation of information, especially in the standard format Industry Foundation Classes (IFC). This work contributed to demonstrate, not only that there are still problems concerning the interoperability between BIM software, but also the advantages of employing BIM for building maintenance purposes.
\end{abstract}

Keywords: BIM, interoperability, maintenance.

\section{INTRODUCTION}

Building Information Modelling (BIM) is the digital representation of all the physical and functional characteristics of a facility, being used as an information repertoire, which can be shared and updated throughout the facility's life-cycle [1]. The parametric creation process of the BIM model provides a chance of performing an automatic detection of conflicts, of promoting a link between the model and the schedule planning stage (the creation of the 4D model), of interconnecting the model with budgeting data (5D model definition) [2] and of relating the modelling with different processes regarding the facility management and maintenance throughout its life span (referred as the 6D model) [3]. The aggregation of several types of information on a single platform provides a positive value to the model, functioning as a resource that can be accessed directly by countless people, avoiding the expense of time and money in work duplications and allowing the constant update of information.

There is currently a growing concern about the maintenance and upkeep of buildings, not only due to regulatory standards set out in the project, but also the requirement of the users in terms of safety, health and building comfort. BIM models have revealed themselves to be an excellent tool not only during the stage of planning and construction, but also in the maintenance phase, mainly because of its large capacity for storing information associated with the three dimensional (3D) representation [4]. The fact that it is possible to access all the information of the building, through

\footnotetext{
*Address correspondence to this author at the Department of Civil Engineering, IST, ICIST, University of Lisbon, Lisbon, Portugal;

Tel: +351218418336; Fax: +351218497650;

E-mail: zita@civil.ist.utl.pt
}

a single platform, combined with the automatic update of the model whenever changes are made, makes the BIM model very advantageous and promising during the exploration stage of a building, for this way, more reliable and accurate maintenance operations can be achieved [5].

On one hand, getting an accurate and omission free update of the models using the Industry Foundation Classes (IFC) standard, is one of the main difficulties encountered when using BIM models during the exploration stage of a building. On the other hand, maintenance of buildings has proved to be a rather complex task to accomplish, because the identification and analysis of all kinds of failure in construction requires a considerable effort of the agents responsible for maintaining the facility [4]. As such, in this work it was developed an innovative BIM-based software tool, aimed to support the inspection operations of buildings, making them more efficient, due to its rigorous database, allowing the user to identify anomalies in the construction components directly on the BIM model, and associate them with the probable cause, recommended solution, repair method and a photograph [6]. Additionally, it was case study the interoperability between BIM modelling and visualizing software, regarding the preservation of information, especially in the IFC standard.

This work contributed to demonstrate, not only that there are still problems concerning the interoperability between BIM software, but also the advantages of employing BIM for building maintenance purposes.

\section{INTERACTIVE SYSTEM}

This research follows recent previous works concerning the use of Virtual Reality (VR) technology in the mainte- 
nance of buildings activity. The data base worked out in those previous studies were reorganized and used in the present work within a BIM context. The implemented strategy for inspection support concerns three building components, roofs [7], facades [8] and interior walls [9]. The novelty of the present study concerns the use of BIM technology. This work incorporates BIM modelling techniques, programming skills and devices to perform visual exploration tasks. To support the system a data base was created which included a bibliographic research support made in regard to the closure materials used in the roof, and interior and exterior walls of a building, anomalies concerning different kinds of covering material, and corrective maintenance. Repair activities were also studied. The data base compiles the maintenance information selected from the three previous VR applications.

The programming skills of those involved in the project had to be enhanced so that they could achieve the integration of the different kinds of data bases needed in the creation of the system. The interactive application supports on-site inspections and the on-going analysis of the evolution of the degree of deterioration of the coating materials. The following computational systems were used in there development and the scheme of links between software is presented in Fig. (1):

- Revit architecture, in the creation of the 3D model of the building (based on AutoCAD drawings) and saved in the IFC format [10];

- BIM visualizer Navisworks for the interaction capacity with the elements and to realize the integration to the inspection program [11];

- Visual Basic in the creation of all the windows of the inspection application and in the establishment of links between the program and the inspection data base;

- Microsoft Access on the definition of a relational database.

\section{BIM ARCHITECTURAL MODEL}

The architectural BIM model was created, using the Revit Architecture software. In order to illustrate how to carry out the modelling of a building using a BIM based software, a small fraction of real estate development in Cascais, near Lisbon, Portugal, was chosen as case study. The building consists of three floors; the ground floor consists of two dwellings and the remaining floors, four duplex dwellings. Each dwelling consists of bedrooms, toilets, kitchen, living room, hall and balcony.

In the model, all elements represented as walls, floors, ceilings, roof, doors, windows, and handrails, were created by adapting existing 3D parametric objects in the Revit library. The components of decorative character and equipment, such as sofas, chairs, toilets, tables were used directly, merely taking into account the scale factor during their inclusion in the model. The list below presents the orderly steps in the creation of architectural BIM model:

- $1^{\text {st }}$ step: Defining sill elevations of the flooring;

- $2^{\text {nd }}$ step: Importing dwg files;

- $3^{\text {rd }}$ step: Defining the construction platform;
- $4^{\text {th }}$ step: Modifying the contour lines;

- $5^{\text {th }}$ step: Creating, editing and inserting the walls;

- $6^{\text {th }}$ step: Creating, editing and inserting the doors and windows;

- $7^{\text {th }}$ step: Creating, editing and inserting the pavements and the false ceilings;

- $8^{\text {th }}$ step: Creating, editing and inserting the roof;

- $9^{\text {th }}$ step: Creating, editing and inserting the staircases;

- $10^{\text {th }}$ step: Creating, editing and inserting the guardrails;

- $11^{\text {th }}$ step: Inserting the components.

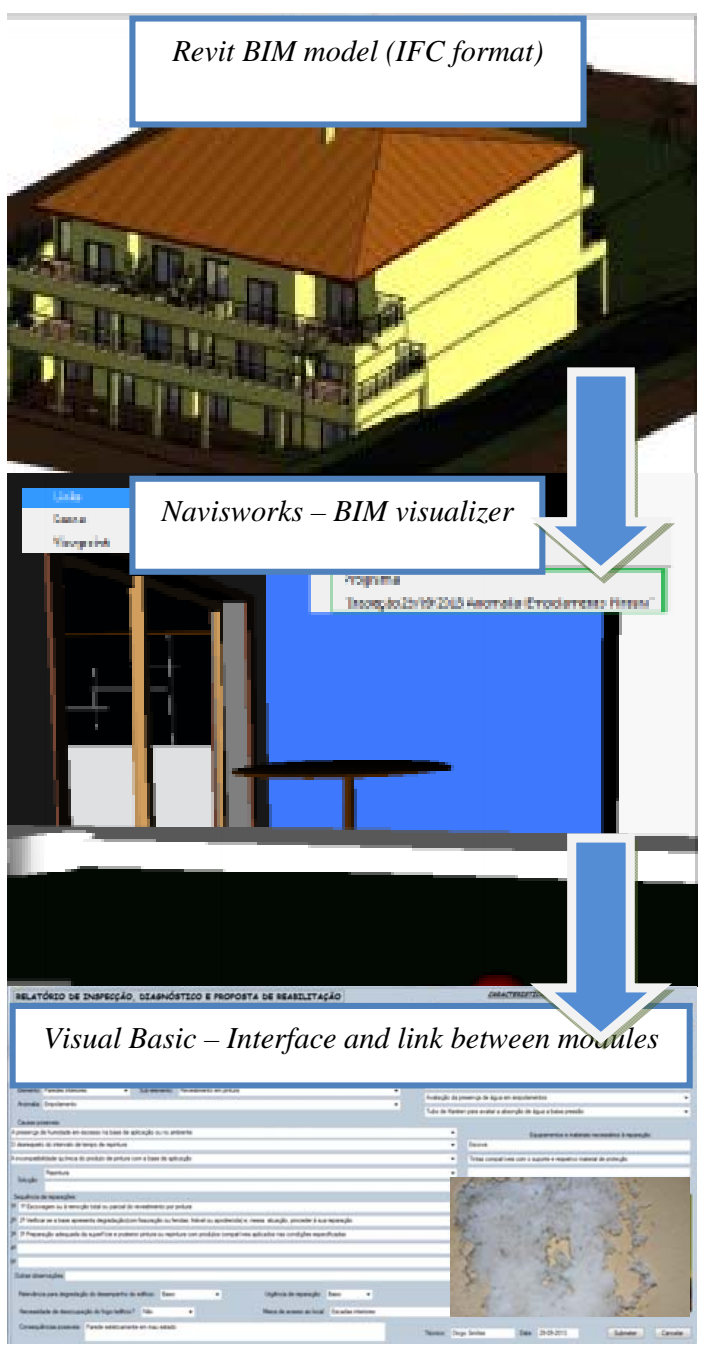

Fig. (1). Sequence of links between software.

Some drawings and projections can be obtained from the architectural model. Fig. (2) shows a plan and a cut and Fig. (3) illustrates the main facade, a general perspective of the model, and one view shot of the interior.

To use the BIM environment as a support to the maintenance activity, the architectural BIM model of the building to be inspected is first created. The composition of each architectural component and the materials used in there covering stays characteristics linked to each object of the model. 
This information can be consulted in an inspection work in the building local, when observing real anomalies. In addition a Visual Basic inspection application was developed to be used in this context.
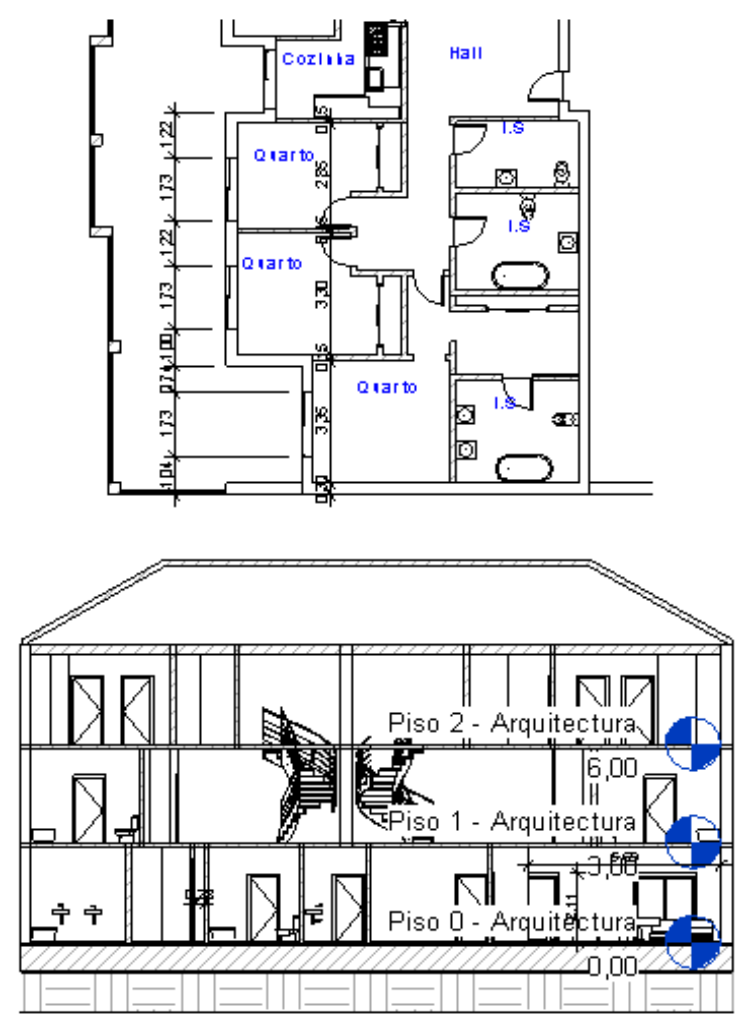

Fig. (2). Ground floor plan and vertical section.
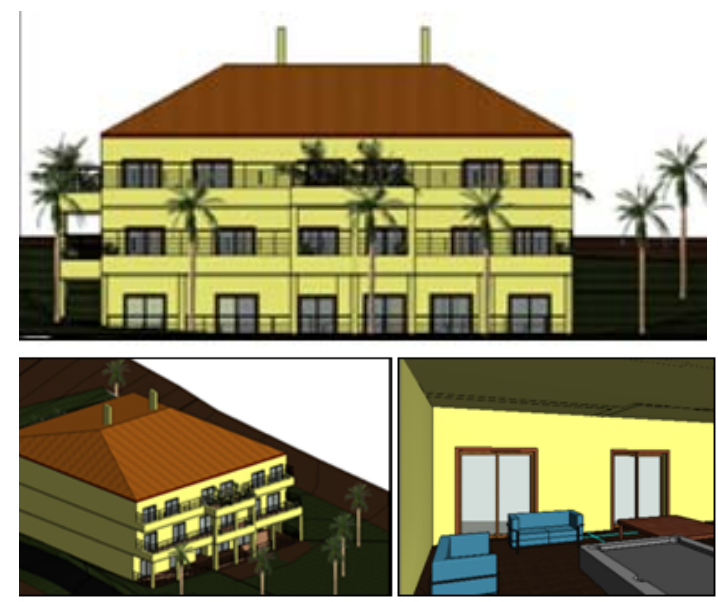

Fig. (3). Main façade, general perspective of the model and interior projection of the 3D model.

\section{INSPECTION PROGRAM}

An inspection programme was implemented to support the maintenance work in a BIM environment. It was developed as an independent application and after linked to the BIM architectural model. The interactive inspection operations sheet, created using the Visual Basic software, has as main objective to support the elaboration of an inspection. In its development the database that was used consisted in the compilation of information from other dissertations also developed for maintenance purposes (using VR technology). The information provided in this work relates to anomalies, causes, solutions and repair methodology concerning constructive components: exterior walls, interior walls and pitched roofs. Therefore, during an inspection, the maintenance expert, when observing an anomaly, can consult the database support to fill out the inspection sheets and select the identified anomaly on the site.

Subsequently, the completed inspection sheet is then converted to the pdf format and inserted into the BIM model. This model should be constantly updated, in order to accurately support the facility with repair and maintenance plans. The developed computer application has its interface illustrated in

Fig (4) An inspection sheet must include some initial information such as identification of the technician, the date of the inspection and the identity and characteristics of the building (address, city, number of floors, year of construction, etc...).

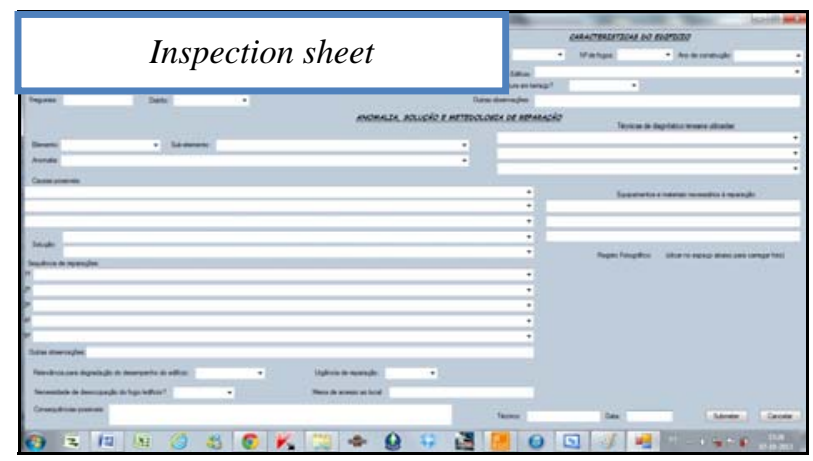

Fig. (4). Interface of the inspection sheet.

The interface allows the user to select the type of element (wall, façade or roof), the sub element (wall - painted covering), and an anomaly included in scrolled lists (linked to the chosen element and sub element). The examples of Fig. (5) shows the considered anomalies linked to a painted wall, as well as the anomalies related to singular point in a roof element. The anomalies considered in each case are listed below in the images of the interface.

Most of this information is selected from ComboBox elements, so your registration is carried in a fast way. A ComboBox element is defined with a combination of a text box and a list box, allowing the filling of the text box with one of the options provided in the list that appears as a descending menu.

In addition, a ComboBox element allows the user to group relations of dependence between them, providing different lists depending on types of elements, that is, the box lists differ according to the option selected in advance. In the developed software tool, this feature is observed between the elements and sub-elements (Fig. 5), among the verified subelements and anomalies (Fig. 5) and between anomalies and possible causes, solutions and repair methodology (Fig. 6). 

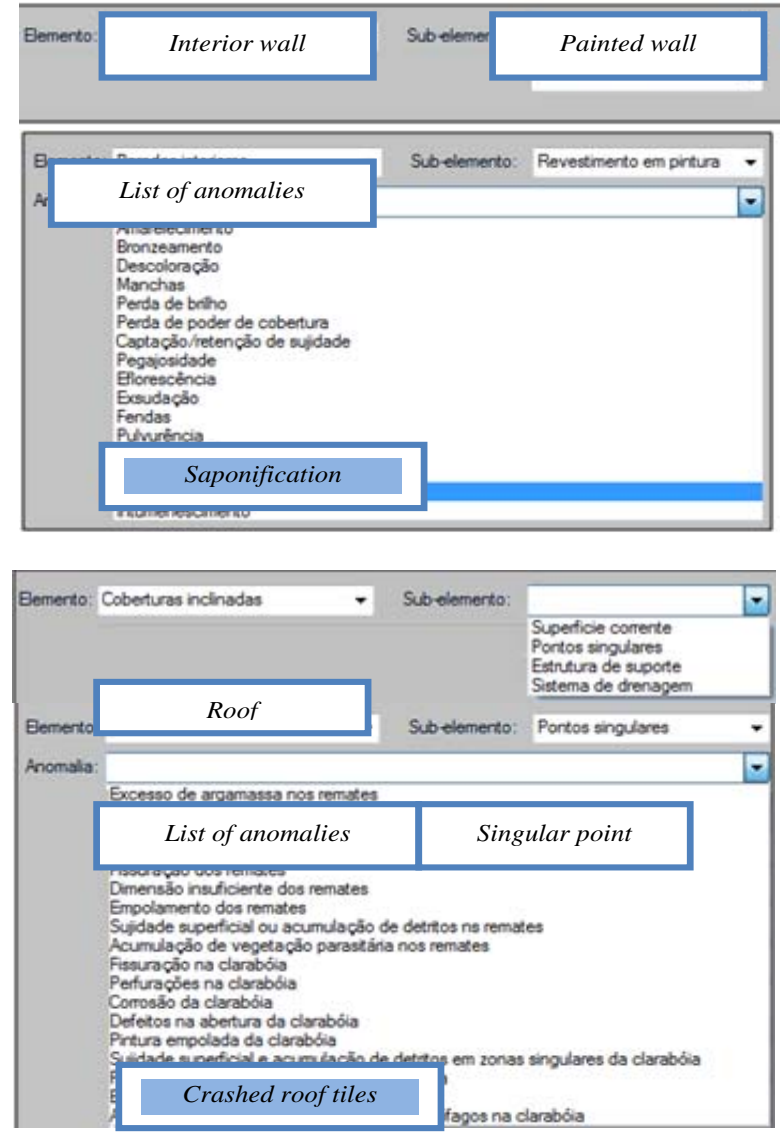

Fig. (5). Sub-elements available when choosing the element and lists of available anomalies according to the chosen element and subelement.

The application also allows you to include a photograph of the anomaly taken at the site and convert the information presented in the sheet of inspection to a document in pdf format. Such possibilities are essential for an inspection sheet, because the addition of a photograph allows the user to recognize the anomaly, its severity and location, and conversion to pdf format enables the user to save the inspection form in a universal format. The result of filling the form is illustrated in Fig. (7). Fig. (8) illustrates another case of inspection (in a facade) as a pdf file report. Next, this Visual Basic application is used when interacting with the model using a BIM visualizer, in realizing an inspection in the local of the building.

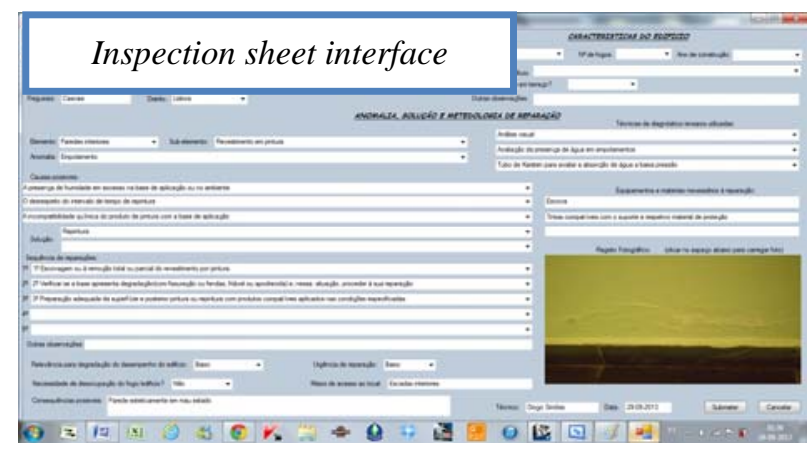

Fig. (7). Interface of the filled out inspection form.

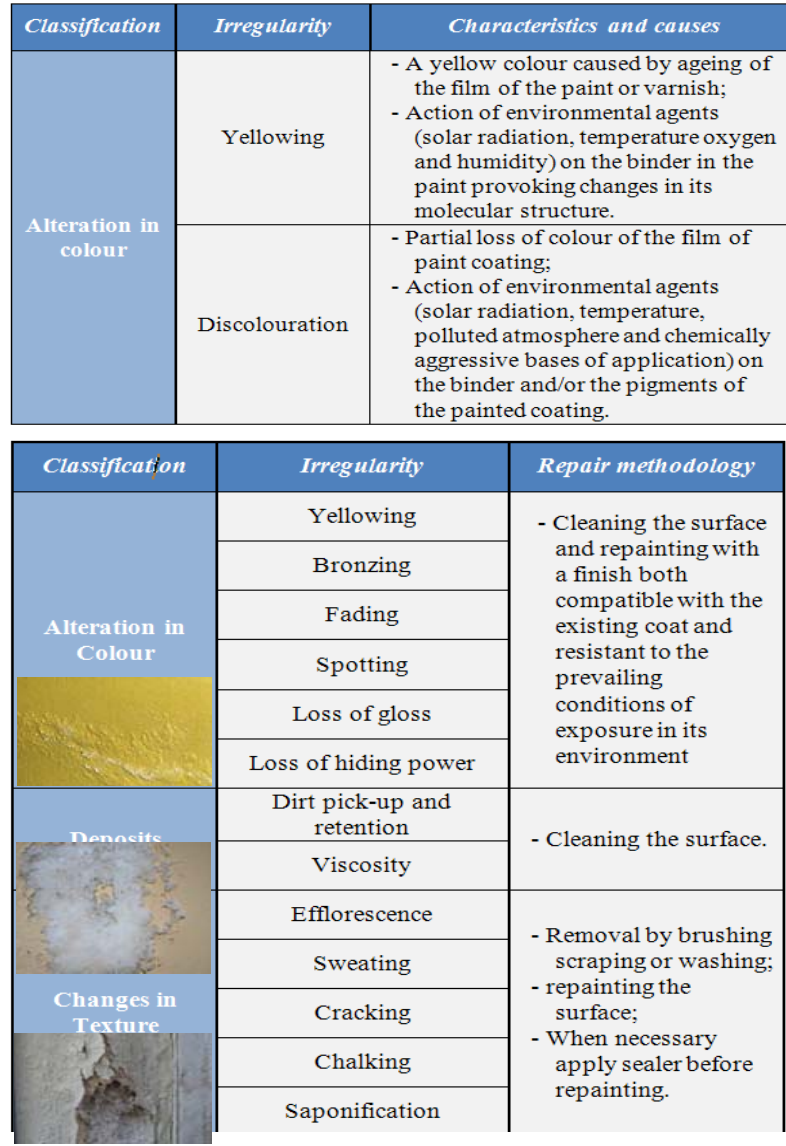

Fig. (6). Classification of anomalies, characteristics, causes and repair methodology related to painted walls.
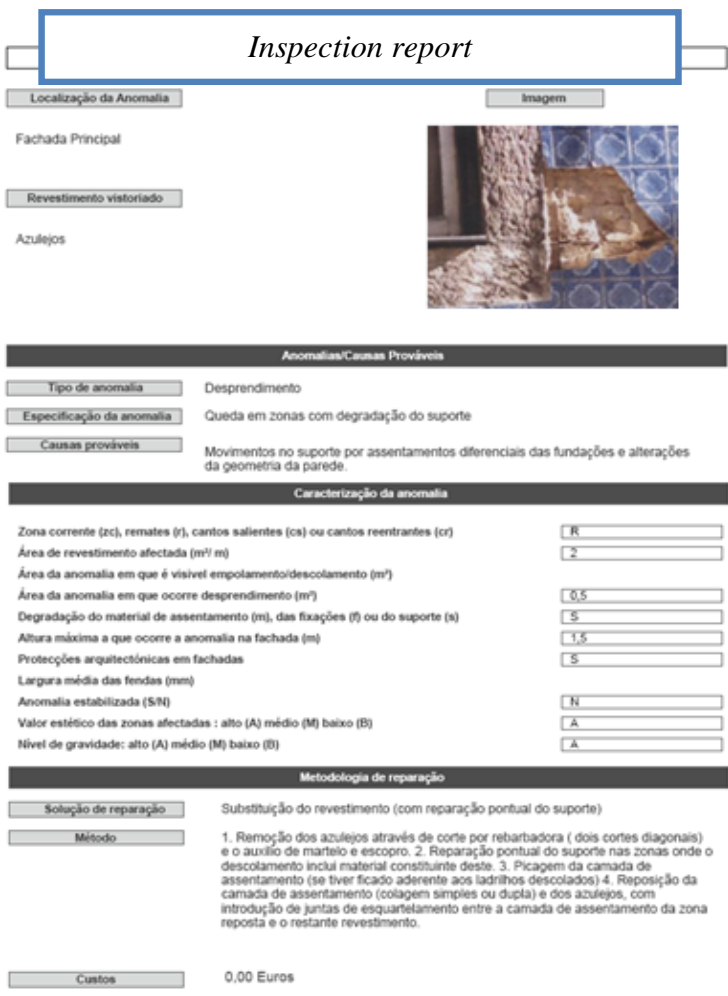

Fig. (8). The inspection pdf sheet. 


\section{BIM MODEL LINKED TO INSPECTION PROGRAM}

A BIM visualizer is an application that enables access to all information created in the BIM model. Unlike the modeling software, navigation and interaction with the model is performed quickly and lighter, and can also be accessed from mobile devices such as smartphones or tablets. This type of application also allows integrating the diverse information from architectural designs, structures, building installations and budgeting, and also allows the analysis of conflict detection.

This item covers how to combine the BIM model of the building, the information from the inspection form, using a BIM visualizer. In this study it was analyzed the degree of interoperability between the BIM modeler and the BIM visualizer (Navisworks). In particular, this analyzes regards data and information transfer in the IFC format from Revit to Navisworks. Furthermore, an inspection form is filled in and, afterwards, saved and included in the model, so that it can be used as a basis for consultation when planning maintenance operations. The data transfer between the BIM modeler and visualizer, in IFC standard, resulted in complete preservation of information and error free. So, it permits to conclude that the degree of interoperability between the used software is efficient in what concerns data transfer.

The only limitations observed were the clutter of information and a lack of storage capacity of the previously predefined colors, which led to the total deprivation of color of the model, as illustrated in Fig. (9).

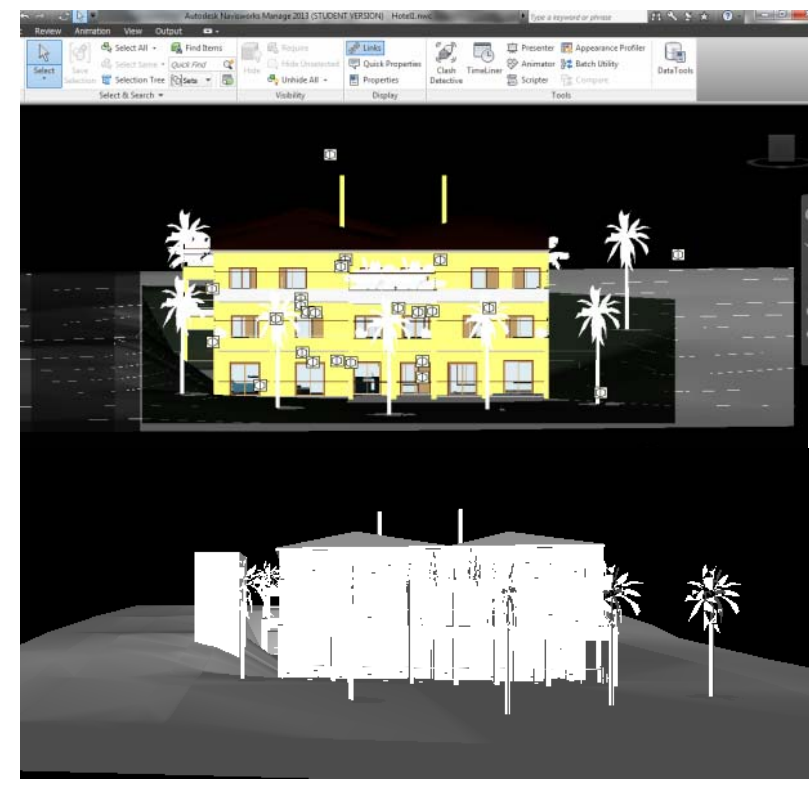

Fig. (9). Navisworks interface showing the colour deprivation in the IFC format.

In an inspection activity the maintenance technician, using the developed application, selects the element where an anomaly was observed, in this case an interior wall (shown in blue in Fig. 10). Through the BIM model, the service technician can identify the constituent materials of the interior wall (Fig. 10) and has the possibility to run the inspection program, by selecting the link "Program", fill out the inspection form and store it in the BIM model, through the creation of a new link.

Let us assume for example, that the inspection sheet was recorded under the name "Inspection 29 Oct. 2013- Anomaly- paint blistering". Whilst planning for maintenance operations, or any other inspection activity, the choice of the element in which lies the anomaly (the wall inside the room depicted in blue in Fig. 10) identifies two associated attachments: the inspection program and a sheet of the inspection carried out on the December 2013, concerning an anomaly called paint blistering (Fig. 11).

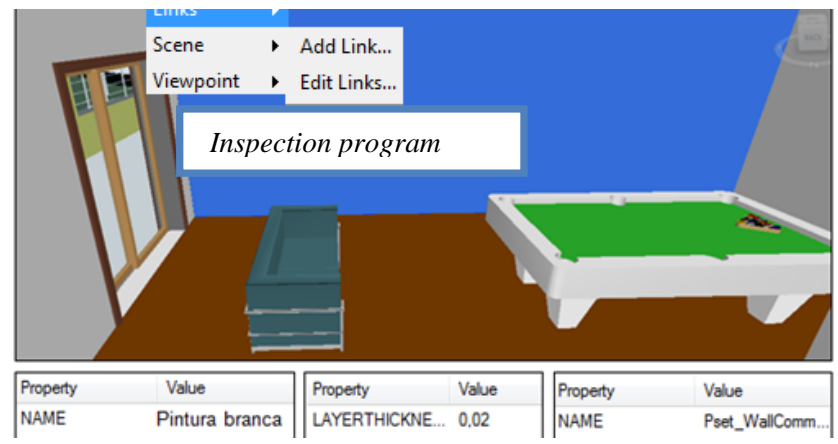

Fig. (10). Selection of an exterior wall and its associated features, and of the link "Program".

By choosing the link "Inspection Dec. 2013 - Anomalypaint blistering", the user is automatically opening the pdf document related to the associated inspection form, i.e. the sheet shown in Fig. (11).

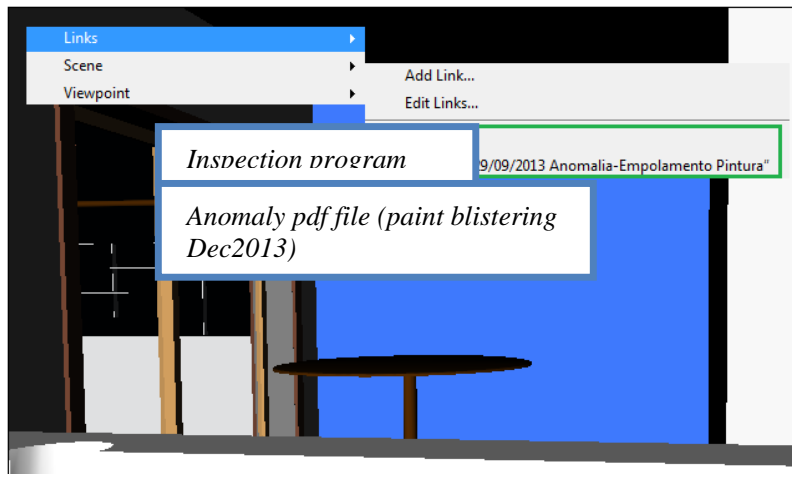

Fig. (11). Selection of the inspection file of the anomaly associated with the inner wall.

This consultation allows us to better understand what the probable causes that originated the new anomaly are. If the problem shows a degree of severity or has been subjected to some kind of repair, the materials used and the exact location of the anomalies that have already been registered (through photography). The example shown in the previous images concerns the detection of an anomaly in the modeled house, characterized as paint blistering irregularity. The respective inspection sheet was adequately filled and the correspondent $p d f$ file was created. After, when manipulating the BIM model, using the visualizer Navisworks, the composition of the wall could be consulted as well as the $p d f$ file of the anomaly observe in the real wall of the building. 


\section{IMPLEMENTATION PROBLEMS}

The creation of the inspection sheet had some problems, particularly concerning the creation of a routine that allows the insertion of any picture on the form, and in obtaining the pdf-sharp library that would allow its conversion to pdf format.

However, the creation of an inspection sheet to support the maintenance of buildings, based on a BIM model would be unsuccessful if the digital modeling of a building wasn't performed. Therefore, parallel to the creation of the inspection form, an architectural BIM model was developed from scratch, being described every step of its development, illustrating the procedures of its establishment and insertion of distinct data type, with the objective of providing the building relevant information, which could be reused. Then, the modeling was exported using the IFC format to a BIM visualizer so that it could be displayed in a fast and efficient manner. The implementation of the model was done not only as a necessity, but also in order to study one of the major obstacles to the implementation of BIM, its interoperability under the IFC format. In fact, this work confirms that the IFC format is not yet fully developed in order to properly implement the information models, as, despite not losing any information, it features it in a disorganized manner, not retaining the color added to the model.

A BIM visualizer allows the representation of BIM models in a simple and fast way, allowing the user to add different models and different documents, programs or notes. As such, a program that supports the inspection of buildings was added to the BIM visualizer software. This combination's main objective is to aid in the maintenance activity of a building, because it allows the maintenance technician to perform inspections with the developed software by automatically running it after selecting the building element in the model. You can also save the inspection form in pdf format by entering it again in the model. So any maintenance technician can consult all the information concerning a given building element, not only its materials, dimensions and physical characteristics, but also its historical anomalies, any intervention that it has been subjected to and their exact location on the element, providing an important aid in keeping the building and therefore the comfort of their users.

Adding the program to the BIM visualizer of is done in a fairly simple way, however, it was observed that some visualizers do not support certain applications, which indicates difficult defect to overcome, when the main purpose of these is the aggregation of information in any form. It was also noted that it still wasn't possible to automatically save the inspection sheet onto the building element selected in the BIM visualizer. Overcoming this obstacle would result in even greater productivity, when filling out the forms and then associating them to the model, this being just one more aspect that would support the association between the inspection program and the BIM visualizer.

\section{CONCLUSION}

Effective facility maintenance is based on a thorough inspection for anomalies. Therefore, an inspection sheet was developed, with the purpose of enhancing the technical inspection, of a tool that lists anomalies, for the constructive element selected, automatically providing, the repair procedure, its main causes and respective solution. Thus inspections are carried out in greater detail, and hence greater chronological and productivity gains can be achieved. The ability to write in pdf format reveals itself most important for subsequent addition to a BIM model. It can be concluded that with this work, a useful program was established to support building inspections and future maintenance operations, which associated with an architectural BIM model, and taking into consideration that the benefits would be greater if the BIM model integrated various specialties, it was demonstrated that the great potential inherent in BIM, as a methodology, can be revealed in the actions of maintenance of a building.

\section{CONFLICT OF INTEREST}

The authors confirm that this article content has no conflict of interest.

\section{ACKNOWLEDGEMENTS}

Declared none.

\section{REFERENCES}

[1] NBIM National Institute of Building Sciences - www.wbdg.org/ pdfs/NBIMSv1_p1.pdf [Accessed: September 2013]

[2] T. Hartmann, J. Gao, and M. Fischer, "Areas of application for 3D and 4D models on construction projects", Journal of Construction Engineering and Management, pp. 776-785, 2008.

[3] C. Eastman, P. Teicholz, R. Sacks, and K. Liston, BIM Handbook$A$ Guide to Building Information Modelling. $2^{\text {nd }} E d$. New Jersey: John Wiley \& Sons, Inc. 2011.

[4] J. Goedert, and P. Meadati, "Integrating construction process documentation into building information modelling", Journal of Construction Engineering and Management, vol. 134, no. 7, pp. 509-516. 2008.

[5] F. Martins, and N. Cachadinha, "New uses of BIM capabilities: support for the work carried out measurement and production of asbuilt models reliable and rich in information to the maintenance phase", $4^{\text {th }}$ National Construction Conference, FCT, University Nova, Lisbon, Portugal, 2012. (in Portuguese)

[6] D.G. Simões, "Building maintenance supported by BIM model", Master thesis in Civil Engineering, Technical University of Lisbon, Portugal, 2013. (in Portuguese)

[7] L. Afonso, "Maintenance of buildings supported on virtual reality technology", Master thesis in Civil Engineering, Technical University of Lisbon, Portugal, 2013. (in Portuguese)

[8] D. Rosario, "Virtual reality technology applied in the maintenance of buildings: interior walls with paint coating", Master thesis in Civil Engineering, Technical University of Lisbon, Portugal, 2011. (in Portuguese)

[9] A. Gomes, "Virtual reality technology applied in the maintenance of facades", Master thesis in Civil Engineering, Technical University of Lisbon, Portugal, 2010. (in Portuguese).

[10] Revit- Autodesk - forums.augi.com/showthread.php?10925Origins-of-Revit\&highlight=revit\%20history [Accessed: September 2014]

[11] Navisworks - Autodesk - www.autodesk.com/products/autodesknavisworks-family/overview [Accessed: September 2014] 